\title{
USUÁRIO DA BUSCA INFORMATIZADA: AVALIAÇÃO DO CURSO MEDLINE / LILACS NO CONTEXTO ACADÊMICO
}

\section{ANGELA MARIA BELLONI CUENCA}

DISSERTAÇÃO DE MESTRADO APRESENTADA À FACULDADE DE SAÚDE PÚBLICA DA UNIVERSIDADE DE SÃO PAULO PARA OBTENÇÃO DO GRAU DE MESTRE

ORIENTADOR: Profa. Dra. MIDORI ISHII 
ANGELA MARIA BELLONI CUENCA

\section{USUÁRIO DA BUSCA INFORMATIZADA: AVALIAÇÃO DO CURSO MEDLINE / LILACS NO CONTEXTO ACADÊMICO}

SÃO PAULO 
LOMBADA

CUENCA, AMB

Usuário da Busca informatizada

ANEXOS 


\section{ANEXO 1}

\section{BASES DE DADOS DISPONÍVEIS NA BIBLIOTECA EM REDE LOCAL}

\section{BASES PRODUZIDAS PELA BIBLIOTECA}

ACERVO: com referências de livros, monografias, congressos, relatórios e materiais similares, incorporados ao acervo da Biblioteca.

HIGEIA: composta por referências bibliográficas e resumos das teses apresentadas à FSP/USP de 1982 em diante; da produção cientifíca dos docentes, de 1986 em diante e dos artigos publicados na Revista de Saúde Pública, editada pela Faculdade, de 1987 em diante.

Base de dados nacional:

AdSAÚDE: com referências bibliográficas e resumos de artigos de periódicos selecionados; de livros e capítulos; documentos não-convencionais produzidos por autores nacionais na área de administração de serviços de saúde. Desde 1986

\section{BASES DE DADOS DE LITERATURA LATINO-AMERICANA}

LILACS: editada pela BIREME (Sistema Latino-Americano e do Caribe de Informação em Ciências da Saúde) divulga a literatura convencional e nãoconvencional sobre ciências da saúde gerada na América Latina e Caribe. Período: 1980 em diante.

Atualizada trimestralmente. Contém no mesmo CD-ROM também outras bases latino- americanas, como: REPIDISCA, LEYS, PAHO, WHOLIS, ADOLEC, ECO, BBO, AdSAUDE dentre outras. 
REPIDISCA: editada pela Rede Panamericana de Informação e Documentação em Engenharia Sanitária e Ciências do Ambiente, com sede no Perú, divulga literatura na área de meio ambiente, engenharia sanitária e áreas afins.

\section{BASES DE DADOS DA LITERATURA INTERNACIONAL}

MEDLINE: editada pela "National Library of Medicine" (EUA), com referências bibliográficas e resumos da literatura de medicina e áreas afins. Abrange o período de 1966 em diante. Atualizada mensalmente.

SOCIOFILE: compilada pelo "Sociological Abstratcs Inc.", contém referências bibliográficas e resumos da literatura sobre sociologia e disciplinas correlatas, incluindo teses. Período: de 1974 em diante. Atualizada quadrimestralmente.

HUMAN NUTRITION: produzida pela CAB (Commowealth Agricultural Bureau), é composta pelos subconjuntos das bases: CAB, MEDLINE e FSTA quanto à literatura sobre nutrição humana. Período: de 1982 em diante. Atualizada trimestralmente.

HEALTH PLAN: editada pela "National Library of Medicine", contém referências bibliográficas e resumos sobre serviços de saúde e administração e planejamento em saúde. Período: de 1981 em diante. Atualizada trimestralmente.

LIFE SCIENCES COLLECTION: compilada pela "Cambridge Scientific Abstracts", contém referências bibliográficas e resumos de publicações sobre biologia, entomologia, ecologia etc. Período: de 1986 em diante. Atualizada trimestralmente.

ERIC - Educational Resources Information Center produzida pelo US Department of Education, indexa cerca de 850 periódicos da área de educação.

Além das bases de dados citadas, a Biblioteca coloca à disposição dos usuários as seguintes bases para localização bibliográfica: 
DEDALUS/USP: banco de dados bibliográficos dos acervos das bibliotecas da Universidade de São Paulo (livros, seriados, teses e produção do corpo docente).

SeCS/BIREME: reúne os acervos de publicações seriadas das bibliotecas da Rede Latino-americana e do Caribe de Informação em Ciências da Saúde.

CCN-IBICT: reúne os acervos de publicações seriadas, de cerca de 1.000 bibliotecas brasileiras compilado pelo Instituto Brasileiro de Informação em Ciência e Tecnologia (IBICT).

UNIBIBLI: contém as referências bibliográficas das teses geradas na USP, UNESP e UNICAMP, bem como os acervos de suas bibliotecas. 


\section{ANEXO 2 \\ Programa do Curso}

\section{CURSO DE ACESSO ÀS BASES DE DADOS EM CD- ROM MEDLINE/LILACS}

\section{Cursos/95}

Horário: $13: 00$ às $17: 00$ hs

Local: Biblioteca da FSP/USP

Participantes: Docentes e Alunos de Pós-Graduação

Responsabilidade: Serviço de Biblioteca e Documentação da Faculdade de Saúde Pública da USP

\section{PROGRAMA}

\section{Módulo 1}

Apresentação da rede local informatizada da Biblioteca.

Apresentação do CD-ROM MEDLINE: Comandos e funções do software; campos disponíveis.

Exercícios práticos de busca simples.

Uso do vocabulário MeSH (descritores).

Estratégia de busca com o uso do thesaurus.

Exercícios práticos de busca com descritores/thesaurus.

\section{Módulo 2}

Bases de dados disponíveis na Biblioteca.

Base de dados LILACS em CD-ROM: Comandos e funções do software; campos disponíveis; uso do vocabulário DeCs.

Exercícios práticos de busca na LILACS.

Comutação Bibliográfica.

Como localizar um documento; como obter o documento.

Estratégia de busca para o tema do aluno.

Obs. Os exercícios serão feitos diretamente nos microcomputadores 


\section{ANEXO 3 \\ Questionário para os participantes do Curso MEDLINE/LILACS}

Caro usuário,

Peço sua especial colaboração no preenchimento deste questionário, o qual tem como objetivo obter subsídios para a avaliação do CURSO MEDLINE/LILACS da Biblioteca da FSP/USP do qual você participou. Por isso sua opinião sobre o Curso é fundamental para alcançarmos esse objetivo.

Essa avaliação fará parte da minha dissertação de mestrado sobre a recuperação da informação e o usuário final, especificamente o caso da Biblioteca da FSP/USP. Sua devolução até 31.5.96 é muito importante!

Agradeço antecipadamente sua disponibilidade no preenchimento do mesmo.

Para qualquer esclarecimento, por favor me procure:

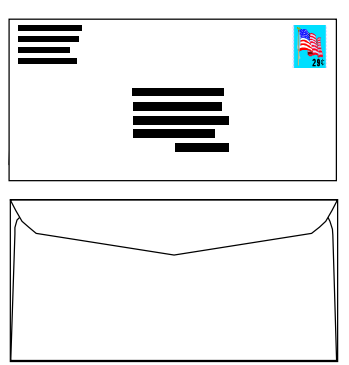

Angela Maria Belloni Cuenca

Biblioteca da Faculdade de Saúde Pública/USP

Av. Dr. Arnaldo, 715

01246-904 - São Paulo, SP - Brasil

E.Mail: abcuenca@usp.br

Residência:9- 011-858 7619

Trabalho: 011-3061.5233 r.2260

Fone/Fax: 011-3064.1462

Nota explicativa

Caso o espaço não seja suficiente para responder, comentar ou justificar a questão, use o verso da folha, indicando o número da pergunta a que se refere.

PARA AGILIZAR A DEVOLUÇÃO USE ENVELOPE SELAdO ANEXO, OU CASO PREFIRA, ENVIE-O POR FAX OU AINDA, ENTREGUE-O NA PRÓPRIA BIBLIOTECA DA FSP(Balcão) 


\section{QUESTIONÁRIO PARA OS USUÁRIOS PARTICIPANTES DO CURSO MEDLINE/LILACS DA BIBLIOTECA DA FSP/USP}

NOME :

(Sua identificação é necessária somente para levantar os dados estatísticos do seu uso das bases na Biblioteca. Para as respostas a seguir será garantido seu anonimato)

PARTE I - ESTA PARTE DO QUESTIONÁRIO TEM POR OBJETIVO A CARACTERIZAÇÃO DO USUÁRIO QUE PARTICIPA DO CURSO MEDLINE/LILACS

1-FORMAÇÃO BÁSICA (Especifique a área)

2-Qual seu último grau acadêmico?

( ) Mestrando

( ) Mestre

( ) Doutorando

( ) Doutor

( ) Outro:

3- A principal atividade que o levou a procurar o Curso foi:

( ) Acadêmica

( ) Profissional (Especifique atividade e instituição)

( ) Outra (Especifique atividade e instituição/empresa)

(Especifique atividade e instituição/empresa)

4- Atualmente, qual sua principal ÁREA DE ATUAÇÃO*?

( ) Administração e Planejamento em Saúde

( ) Epidemiologia e Bioestatística

( ) Cuidados de Saúde

( ) Demografia

( ) Saúde Ambiental

( ) Nutrição

( ) Outra:

(Caso considere esta classificação não adequada à sua atuação)

5- Como ficou sabendo do Curso?

( ) Através do orientador de pós-graduação

( ) Através de colegas

( ) Na própria Biblioteca da FSP. Como?

( ) Em aula de Orientação Bibliográfica da FSP

( ) Outro:

\footnotetext{
* Esta classificação está de acordo com as categorias definidas no vocabulário DeCS da Base de Dados LILACS da BIREME, 1995.
} 


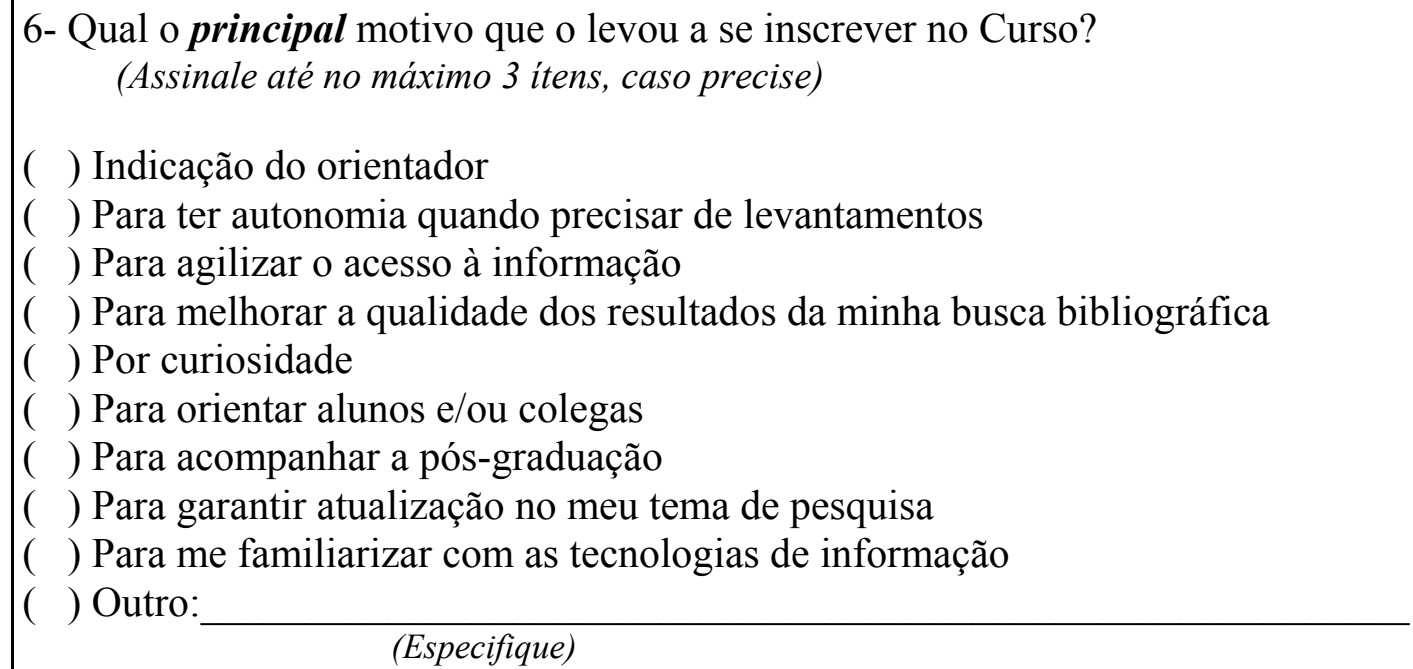

7- Onde você costuma obter os documentos referentes a literatura da sua área? (Assinale mais de um item, caso precise)

( ) Na biblioteca da FSP

( ) Em outras bibliotecas.Indique:

( ) Solicita separata ao autor

( ) Com colegas

( ) Outras formas:

8- Quando você não consegue obter o documento, como soluciona o problema?

(Assinale mais de um item, caso precise)

( ) Utiliza os dados do resumo do documento

( ) Utiliza as informações já citadas em outros trabalhos

( ) Desiste de usar o documento

( ) Nunca me ocorreu

9- Você já conhecia as bases Medline e Lilacs antes da participação nesse Curso?

( ) $\operatorname{Sim}$

( ) Não

10- Em caso positivo, onde?

( ) No seu local de trabalho

( ) Em sua residência

( ) Em instituições acadêmicas

( ) Em biblioteca.Qual? 
PARTE II - ESTE MÓDULO DO QUESTIONÁRIO TEM POR OBJETIVO A AVALIAÇÃO DO CURSO MEDLINE/LILACS QUANTO A SUA ESTRUTURA, CONTEÚDO E METODOLOGIA

O conteúdo do Curso está descrito abaixo para facilitar as respostas deste módulo.

Apresentação da rede local automatizada da Biblioteca

Apresentação do CD-ROM MEDLINE:Comandos e funções do software; campos disponíveis

Exercícios práticos de busca simples

Uso do vocabulário MESH (descritores)

Estratégia de busca com o uso de thesaurus

Exercícios práticos de busca com descritores/thesaurus

Bases de dados disponíveis na Biblioteca

Base de dados CD-ROM LILACS

Exercícios práticos de busca na LILACS

Como localizar um documento nas bases de dados

Comutação bibliográfica: como obter o documento

Estratégia de busca para o tema do aluno

11- Na sua opinião, que conhecimentos prévios deve ter o aluno para melhor acompanhar o curso? (Assinale mais de um item, caso precise)

( ) Básico de informática

( ) De uso de bases de dados

( ) Dos descritores principais do tema a ser pesquisado

( ) De inglês

( ) Nenhum dos indicados

( ) Todos

12 Você considerou as informações sobre a base de dados MEDLINE:

( ) Insuficientes

( ) Suficientes

( ) Excessivas

13-Caso INSUFICIENTES o que ficou faltando?

( ) Maior detalhamento sobre o software

( ) Maior detalhamento sobre a estrutura da base

( ) Mais informações sobre a abrangência de assuntos da base

( ) Maior tempo com os exercícios práticos

( ) Outro. Especifique:

14-Caso EXCESSIVAS o que você diminuiria?

( ) As informações sobre o software

( ) As informações sobre a estrutura da base

( ) A prática nos terminais

( ) Outro.Especifique: 
15-Quanto à base de dados LILACS, você considerou o conteúdo do Curso:

( ) Insuficientes

( ) Suficientes

( ) Excessivas

16-Caso INSUFICIENTES o que ficou faltando?

( ) Maior detalhamento sobre o software

( ) Maior detalhamento sobre a estrutura da base

( ) Mais explicações sobre a abrangência de assuntos da base

( ) Maior tempo com os exercícios práticos

( ) Outro. Especifique:

17-Caso EXCESSIVAS o que você diminuiria?

( ) As informações sobre o software

( ) As informações sobre a estrutura da base

( ) A prática nos terminais

( ) Outro. Especifique:

18-Indique quais ítens não foram cumpridos na programação do Curso?

(Caso precise veja conteúdo do curso na página anterior)

( ) Estratégia de busca para o seu tema

( ) Como localizar o documento

( ) Comutação Bibliográfica

( ) Todos foram cumpridos

19- As informações sobre como localizar e obter documentos (Comutação

Bibliográfica), você considerou:

( ) Muito útil

( ) Útil

( ) Pouco útil

( ) Indiferente

20- O que você alteraria neste Curso?

( ) Colocaria mais aulas práticas para reforçar o conteúdo

( ) Como usar outras bases disponíveis na rede local

( ) Dividiria em 2 Cursos, um de Medline e outro Lilacs

( ) Outro:

21-O Curso tem a duração de 8 horas. Na sua opinião, para esse conteúdo a carga horária:

( ) Está adequada

( ) De 2 a 4 horas seria suficiente

( ) De 4 a 6 horas seria suficiente

( ) De 9 a 12 horas seria adequada

( ) Mais que 12 horas 
22- Quanto à metodologia do Curso você considerou:

( ) Adequada

( ) Mais ou menos adequada

( ) Inadequada

23- Caso INADEQUADA ou MAIS OU MENOS o que você sugere?

24- Quanto ao material didático distribuído durante o Curso (apostila, folders, regulamentos e programa), você considerou:

( ) Insuficiente.Comente:

( ) Suficiente

( ) Excessivo.Comente:

PARTE III - ESTE MÓDULO DO QUESTIONÁRIO TEM POR OBJETIVO AVALIAÇÃO DO USUÁRIO QUANTO A UTILIZAÇÃO DAS BASES DE DADOS APÓS A PARTICIPAÇÃO NO CURSO

25-Após sua participação no curso MEDLINE/LILACS, você executou buscas nas bases da Biblioteca, ou seja, realizou qualquer forma de busca você mesmo, ou via bibliotecário (inclusive pelo DSI)

( ) $\mathrm{Sim}$

( ) Não

26-Em caso NEGATIVO, qual o motivo?

(Caso precise assinale mais de um item)

( ) Não tive necessidade de fazer busca nesse tempo após o Curso

( ) Não consegui acesso aos computadores da biblioteca (sala fechada, rede fora do ar, falta de bibliotecário,etc)

( ) As informações recebidas no Curso não foram suficientes para que eu mesmo pudesse executar a busca

( ) Não me senti suficientemente familiarizado com o vocabulário especializado

( ) Não encontrei facilidade para usar o serviço de levantamentos bibliográficos da biblioteca

( ) Não encontrei bibliotecário disponível para orientar minha pesquisa

( ) Prefiro fazer minhas buscas em bibliografias impressas

( ) As bases disponíveis na rede da biblioteca não contemplam meu assunto

( ) Não dispunha de computador para verificar o resultado fora da biblioteca

( ) Outro: 
27-Em caso POSITIVO, você realizou as buscas bibliográficas:

( ) A-com autonomia, sem que o bibliotecário fizesse por você

( ) B- somente por intermédio do bibliotecário

( ) C- de ambas as formas, com autonomia e também via bibliotecário

Se você assinalou o item $A$ responda as questões 28 até 47 exceto a 45

Se você assinalou o item $\boldsymbol{B}$ passe para as questões 45 a 47

Se você assinalou o item $C$ responda as questões 28 até 47

28-Qual o principal motivo que o leva a realizar, você mesmo, sua busca bibliográfica?

( ) Rapidez

( ) Autonomia

( ) Segurança

29-Se você respondeu rapidez, assinale o item mais pertinente:

( ) Fica mais rápido conseguir o que preciso

( ) O serviço de levantamento está sempre sobrecarregado

( ) O serviço de levantamento não entrega o resultado na hora

( ) Todos

30-Se você respondeu autonomia, assinale o item mais pertinente:

( ) Uso as bases quando quero

( ) Altero minha estratégia de busca quando necessário

( ) Gosto de ter autonomia no acesso à informação

( ) Todos

31-Se você respondeu segurança, assinale o item mais pertinente:

( ) Confio mais na minha busca

( ) Fico conhecendo melhor o universo da literatura na minha área

( ) Mantenho familiaridade com o acesso às bases

( ) Todos

32-Você prepara sua estratégia de busca antes de ir até o terminal?

( ) Nunca preparei

( ) Às vezes

( ) Faço sempre

( ) Resolvo na hora da busca

Todo sistema de informações possui seu vocabulário especializado próprio, o chamado vocabulário controlado, que nas bases MEDLINE e LILACS correspondem, respectivamente, aos descritores do MeSH (Medical Subjects Headings) e do DeCS (Descritores em Ciências da Saúde).

33-Na sua opinião o vocabulário especializado para a base MEDLINE:

( ) Facilita a sua busca bibliográfica

( ) É dispensável para o resultado final da busca

( ) É indispensável para o resultado final da busca

( ) Seria mais útil se fosse em português

( ) Não tenho opinião a respeito 
34-E para o uso da base LILACS, o vocabulário DeCS:

( ) Facilita a sua busca bibliográfica

( ) É dispensável para o resultado final da busca

( ) É indispensável para o resultado final da busca

( ) É útil por ser em português

( ) Não tenho opinião a respeito

Há na literatura da área da ciência da informação, tendência no uso da chamada linguagem natural de recuperação, que seria a busca realizada por termo livre (sem o uso dos descritores).

35-Na sua opinião a busca por termo livre:

( ) Permite chegar ao mesmo resultado que a feita com os descritores

( ) Dependendo do assunto é mais fácil

( ) É mais fácil sempre

( ) O deixa mais seguro

( ) Usando termo livre consigue chegar ao descritor que precisa

( ) Não tenho opinião

( ) Outro:

36- Ao fazer você mesmo sua busca, precisou de ajuda do bibliotecárioem alguma situação?

( ) $\mathrm{Sim}$

( ) Não

37-Em caso POSITIVO, em qual dos ítens abaixo?

( ) Na gravação dos resultados

( ) Na seleção da base adequada

( ) No esclarecimento da estratégia de busca

( ) Na compreensão dos campos das bases de dados

( ) No uso do vocabulário específico de cada base

( ) Outro:

38-Quanto à relevância dos resultados das buscas que executa, você geralmente as considera:

( ) Muito relevantes - $100 \% \mid--90 \%$ do que recupera é pertinente ao assunto

( ) Relevância entre $90 \mid--70 \%$

( ) Relevância entre $70 \mid--50 \%$

( ) Abaixo de 50\% Comente:

39- $O$ fato de haver restrição quanto à gratuidade na recuperação das citações (200 em disquete ou 30 em papel) dificulta o uso das bases?

( ) $\operatorname{Sim}$

( ) Não

( ) Indiferente 
40- Caso positivo, que critério você considera mais adequado?

( ) Número ilimitado de citações recuperadas para todos os usuários

( ) Número ilimitado de citações recuperadas somente para a categoria docentes

( ) Número ilimitado de citações recuperadas para as categorias alunos e docentes da FSP

( ) Outro. Especifique:

41- $\mathrm{O}$ fato de precisar de um funcionário para verificar seu disquete, ou entrar na rede ou anotar seu assunto e citações recuperadas, dificulta sua ida às bases de dados?

( ) $\mathrm{Sim}$

( ) Não

Comente:

42- A localização dos terminais disponíveis para o seu uso na Biblioteca está adequada?

( ) $\operatorname{Sim}$

( ) Não

43- Caso NEGATIVO, assinale o motivo:

( ) Sou interrompido por colegas/funcionários

( ) Não há silêncio suficiente para minha concentração

( ) Não há privacidade

( ) Não há espaço para anotações ao lado dos terminais

( ) Todos

( ) Outro.

Comente:

44- Na obtenção do resultado da sua busca, o que considera mais adequado?

( ) Verificar o resultado na própria tela

( ) Imprimir o resultado na hora

( ) Gravar em disquete

( ) Enviar via Internet

45- Qual o motivo que o levou a solicitar sua busca bibliográfica via bibliotecário, após o treinamento?

(Assinale mais de um item caso precise)

( ) A sala dos terminais não estava disponível (rede fora do ar, sala fechada, sem bibliotecário, etc)

( ) A base que precisei não estava disponível na rede

( ) O período de busca que precisei não estava disponível na rede

( ) Confio mais na busca feita pelo bibliotecário

( ) Não tenho tempo suficiente para fazer a busca

( ) Não tenho familiaridade com as bases por isso demoro a executá-la

( ) Tenho dificuldade em lidar com essas tecnologias

( ) Outro: 
Parte IV - OPINIÃO FINAL

46- Você acha que a Biblioteca da FSP deve manter Curso dessa natureza?

( ) $\mathrm{Sim}$

( ) Não

Comente:

47-Você acha que mesmo tendo participado do Curso, o usuário deve contar também com o serviço de levantamento realizado pelo bibliotecário?

( ) $\operatorname{Sim}$

( ) Não

Comente:

Caso tenha qualquer sugestão quanto ao Curso, utilize este espaço ou o verso da folha. 


\section{ANEXO 4 \\ Roteiro para coleta de dados junto aos bibliotecários sobre o desenvolvimento do Curso MEDLINE/LILACS.}

\section{Sobre o preparo do Curso:}

1- Sua opinião sobre: planejamento, metodologia, conteúdo e estrutura do Curso; formação das turmas, divulgação junto aos usuários, programa proposto, prática monitorada horário, número de alunos por turma e material distribuído.

o Curso?

2- Que conhecimentos prévios deve ter ter o aluno para melhor acompanhar

3- Você acha que o fato do aluno ter alguma experiência no uso da informação e de bibliotecas é fator facilitador para a procura de Curso dessa natureza?

\section{Sobre o andamento do Curso:}

4- Qual o tipo de queixa o aluno teve durante o Curso?

5- Sua observação sobre aqueles sem experiência em informática e inglês.

6- A apostila é necessária para acompanhamento do Curso? Porquê?

\section{Sobre desempenho após}

7- Quanto ao uso das bases, após o Curso, sua opinião sobre: restrição à gratuidade, controle de uso das bases de dados, localização dos computadores destinados ao usuário final.

8- O que observou sobre a experiência no uso do vocabulário controlado e do termo livre daqueles que realizam buscas com autonomia?

9- Qual o aspecto mais positivo do Curso? egresso Curso.

10- Sua opinião sobre prestar ajuda, no momento da busca, ao usuário

11 - Porque o usuário capacitado procura os serviços de RI depois?

12-Quais fatores foram facilitadores ou dificultadores no seu trabalho junto ao usuário após a implantação do Curso Medline/Lilacs?

\section{Sobre a manutenção do Curso e dos serviços de RI:}

13- Sua opinião sobre a necessidade de manutenção desse Curso.

14- Sua opinião sobre a manutenção dos serviços intermediados pelo bibliotecário para os egressos do Curso.

15- O que falta para o usuário final, hoje, nessa modalidade de capacitação? 


\section{ANEXO 5}

Modelo de planilha para registro de uso das bases da Biblioteca 
